\title{
GENETIC EFFECTS OF SPERMATOGONIAL IRRADIATION ON GROWTH AND AGE AT SEXUAL MATURITY IN RATS
}

\author{
B. A. TAYLOR ${ }^{1}$ AND A. B. CHAPMAN \\ Genetics Laboratory, University of Wisconsin, Madison, Wisconsin 53706
}

Received April 3, 1969

NTEREST in the genetic effects of irradiation on quantitative characters usual-

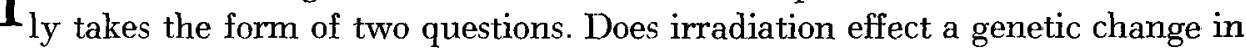
the mean of quantitative characters such as human intelligence? Does irradiation induce genetic variance in quantitative characters that could be utilized by the plant or animal breeder for genetic improvement?

Experimental data relevant to these questions are scanty, especially in mammals, and the results of different experimenters are frequently inconsistent.

The present data were collected in a long-term experiment designed primarily to estimate the frequency of induction of mutations affecting fitness.

\section{MATERIALS AND METHODS}

Most of the details of the experimental procedures have been given previously (TAYLor and Crampman 1969). Briefly, the experiment consisted of comparing an irradiated population with a contemporaneous control population. Both populations originated in the same highly inbred line of rats $\left(\mathrm{MI}_{4}\right)$. The males of the treated line received a fractionated $450 \mathrm{r}$ dose $(d)$ of $\mathrm{X}$ rays each generation administered as 100,150 , and $200 \mathrm{r}$ fractions at 10,12 , and 14 weeks of age. These lines were continued by restricted random mating. Additional matings were made between full sibs in generations 3,4 , and 6 to 14 .

Body weights were taken at 21, 42, and 69 days of age. Body weights were recorded to the nearest gram. Beginning at 28 days of age, females were checked daily for the opening of the vagina. This was considered to be an indication of sexual maturity.

\section{THEORY AND METHODS OF ANALYSIS}

Assumptions: No clear pattern for the effect of irradiation on quantitative characters in mammals has as yet been established. As a working hypothesis the following model will be assumed:

(i) Mutations affecting body weight and age at vaginal opening are neutral with respect to fitness. (ii) These mutations do not exhibit epistasis. (iii) Genotype-environment interaction is unimportant within the range of environments encountered in this experiment. (iv) The effects of sex-linked mutations are negligible.

Accumulation of mutations affecting quantitative characters: Since only one parent is irradiated, the average amount of cumulative radiation exposure in the

\footnotetext{
Published with the approval of the Director of the Agricultural Experiment Station. Paper No. 1288 from the Genetics Laboratory. This work was supported in part by contract AT(11-1)697 of the Atomic Energy Commission

${ }_{1}$ Present address: The Jackson Laboratory, Bar Harbor, Maine 04609. 
treated line in the $n$th generation is $n d$ in the absence of selection, where Generation 1 denotes the first generation whose sires were treated and $d$ is the dose of radiation administered to males each generation in roentgens.

In generation $n$ of the irradiated inbred group a fraction $\mathbf{F}$ of the mutations inherited by generation $n-2$ would be expected to have become homozygous where $\mathbf{F}$ is the inbreeding coefficient. The remaining fraction $(1-\mathbf{F})$ of the mutations would be in the heterozygous condition in generation $n$ as would the mutations that occurred in the two preceding generations. The amount of irradiation exposure relevant to heterozygous effects in the irradiated groups in generation $n$ is:

$$
\begin{aligned}
\mathrm{A}_{n} & =(1-\mathbf{F})(n-2) d+2 d \\
& =[n-\mathbf{F}(n-2)] d .
\end{aligned}
$$

By similar reasoning the amount of radiation exposure put to test in the irradiated inbreds of generation $n$ relevant to the homozygous effects of mutations is:

$$
\mathbf{a}_{n}=\mathbf{F}(n-2) d / 2 \text {. }
$$

Spontaneous mutations exhibiting directional dominance would tend to differentiate the inbreds from the outbreds. Haldane (1936) has calculated that in the absence of selection, the probability of heterozygosity at a locus in a line maintained by full-sib mating for many generations is $12 m_{i}^{\prime}$, where $m_{i}^{\prime}$ is the mutation rate. After the beginning of the experiment (and restricted random mating), the amount of heterozygosity would increase by $2 m_{i}^{\prime}$ each generation. If we assume that dominance is complete and unidirectional, the exposure to recessive mutations affecting quantitative characters would be approximately:

$$
\mathbf{a}_{n}^{\prime}=\mathbf{F}(n+8) \text {. }
$$

The effects of spontaneous and induced mutations on the mean of the character can be expressed in the following terms:

Let $m_{i}$ be the induced mutation rate per roentgen at the $i$ th locus to an allele with homozygous effect $t_{i}$ and heterozygous effect $h_{i} t_{i}$ on the character, and let $m_{i}^{\prime}$ be the spontaneous mutation rate at the $i$ th locus to a recessive allele with homozygous effect $\mathrm{t}_{i}^{\prime}$. Summing over all loci, the expected deviation of the mean of a particular group from the mean of the control outbreds in the $n$th generation is:

$$
\Delta_{n}=\Sigma m_{i} \mathrm{~h}_{i} \mathrm{t}_{i} \mathrm{~A}_{n}+\Sigma m_{i} \mathrm{t}_{i} \mathrm{a}_{n}+\Sigma m_{i}^{\prime} \mathrm{t}_{i}^{\prime} \mathrm{a}_{n}^{\prime} .
$$

The quantities $\Sigma m_{i} \mathbf{h}_{i} \mathrm{t}_{i}, \Sigma m_{i} \mathrm{t}_{i}$, and $\Sigma m_{i}^{\prime} \mathrm{t}_{i}^{\prime}$ can be estimated from the data, and the ratio

$$
\bar{h}=\frac{\Sigma m_{i} h_{i} t_{i}}{\Sigma m_{i} t_{i}}
$$

may be regarded as an estimate of the average dominance. This average is weighted by $m_{i} t_{i}$ and is meaningful only if the $t_{i}$ 's are essentially all of the same sign. If the $t_{i}$ 's are negative, $\bar{h}$ 's of one, zero, or less than zero would indicate complete dominance, complete recessivity, or overdominance of induced mutations, respectively. On the other hand, if the $t_{i}$ 's are positive, $\bar{h}$ 's of zero, one, or greater 
than one would imply complete recessivity, complete dominance, or overdominance, respectively.

Statistical methods: The traits under study, body weights and age at vaginal opening, may be affected by many environmental as well as genetic circumstances. For this reason, comparisons are made within generation-mating group, and the sexes are analyzed separately. Littermates share a common environment, so variation between litters is taken into account in analysis of betweengroup differences. The traits are adjusted for parity, age of dam, litter size at birth, and litter size at 21 days by multiple covariance analysis.

The effects of mutations on the means are estimated by making orthogonal comparisons within each generation-mating group, and regresssing the differences on $\mathrm{a}_{n}=\frac{\mathbf{F}(n-2) d}{2}, \mathrm{~A}_{n}=[n-\mathbf{F}(n-2)] d$ and $\mathrm{a}_{n}^{\prime}=\mathbf{F}(n+8)$ in a weighted multiple regression analysis through the origin. The test for nonlinearity should reflect whether or not natural selection, epistasis, genotype-environment interaction, and/or other complicating factors are playing roles in the changes from generation to generation. This method of analysis is essentially the same as the method used previously for litter-size data (TAYLOR and CHAPMAN 1969).

Two methods are used to test for an increase in variance due to irradiation. The first method compares the within-litter variance of control and irradiated groups. The comparisons are made within mating systems for each different mating group. Any increase observed in the outbred comparison would reflect one half of the variation due to heterozygous effects. The inbred comparisons should reflect portions of both heterozygous and homozygous effects of induced mutations on variance.

The other method of detecting a variance increase involves calculating the regression of offspring on parent for the different traits. This method permits the estimation of the additive variance increase.

Under random mating the regression of offspring on sire is:

$$
b_{\mathrm{os}}=\frac{0.5 \sigma_{\mathrm{A}}^{2}}{\sigma_{\mathrm{T}}^{2}}
$$

The corresponding offspring-on-dam regression is:

$$
b_{\mathrm{od}}=\frac{0.5 \sigma_{\mathrm{A}}^{2}+\sigma_{\mathrm{ME}}}{\sigma_{\mathrm{T}}^{2}}
$$

where: $\sigma_{A}^{2}$ is the additive genetic variance, $\sigma_{M E}$ is the covariance between the environmental deviation of the dam and the environmental deviation of the offspring, and $\sigma_{T}^{2}$ is the total phenotypic variance. Covariances between parent and offspring due to different levels of additive $\times$ additive epistatic effects, due to transmitted and direct maternal effects, and to variance from direct maternal effects are assumed to be unimportant contributors to these regressions. The regression coefficients were calculated as the ratio of the covariance between off- 
TABLE 1

Analysis of variance and covariance illustrating the procedure used in estimating the regression of offspring on parent

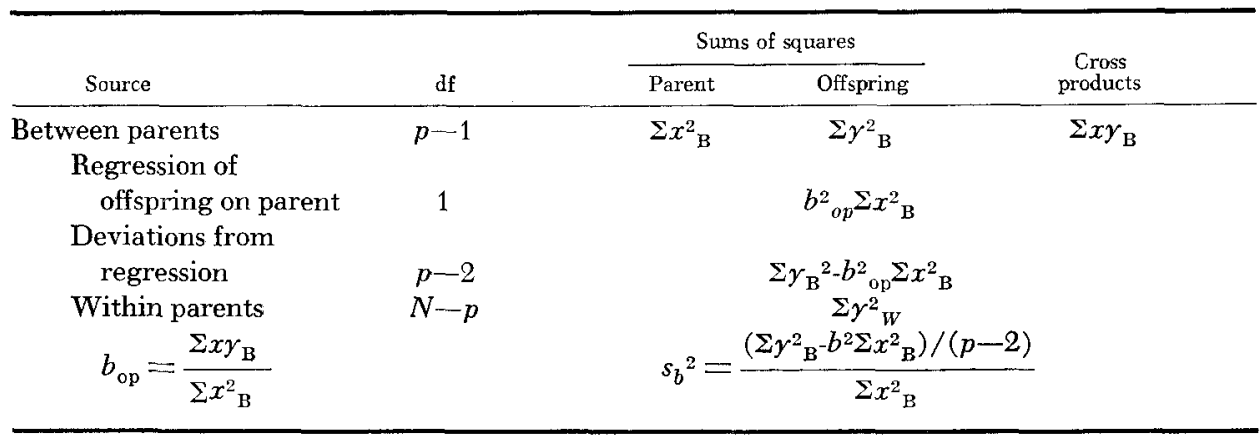

spring and parental records, where each offspring record was given equal weight and each parental record was repeated for each offspring in calculating the sums of squares and cross products. Table 1 shows the analysis of variance and covariance procedure. $N$ is the total number of animals, $p$ is the number of parental families, $\Sigma x_{\mathrm{B}}^{2}, \Sigma y_{\mathrm{B}}^{2}$ and $\Sigma x y_{\mathrm{B}}$ are the corrected sums of squares and cross products among parental families. $\Sigma y_{\mathrm{W}}^{2}$ is the sum of squares among progeny within the same parental family.

Individuals which lacked a record (mortality, missing on weigh day, etc.) for any of the traits, were excluded from the analysis. This tended to exclude unhealthy animals and also facilitated the analysis. Selection of the data in this way should make these results largely independent of effects on survival which are analyzed by different methods.

\section{RESULTS AND DISCUSSION}

Adjustment of the data: The analysis of covariance provides a test for the homogeneity of regression coefficients among the different classes. The test was carried out for each of the traits in each mating group. The assumption of homogeneity was not disputed statistically in 72 of 75 cases in the male analyses at the $95 \%$ confidence level. For the female data, the assumption of homogeneity was not disproved in 89 of 99 tests. Although the latter frequency of significance was about twice that expected by chance, "significance" is questionable since not all of these tests were independent. It is concluded that some heterogeneity may exist but it seems doubtful if it is large enough to invalidate the subsequent analyses. The means of the different classes were therefore adjusted, and the variances of the adjusted means were calculated.

Effects on means: The adjusted means are presented in Tables 2 through 4 . Differences between control and irradiated means within mating group and mating system are also presented. The signs of these differences for the different traits show a similar pattern in both sexes; the irradiated animals in most cases 


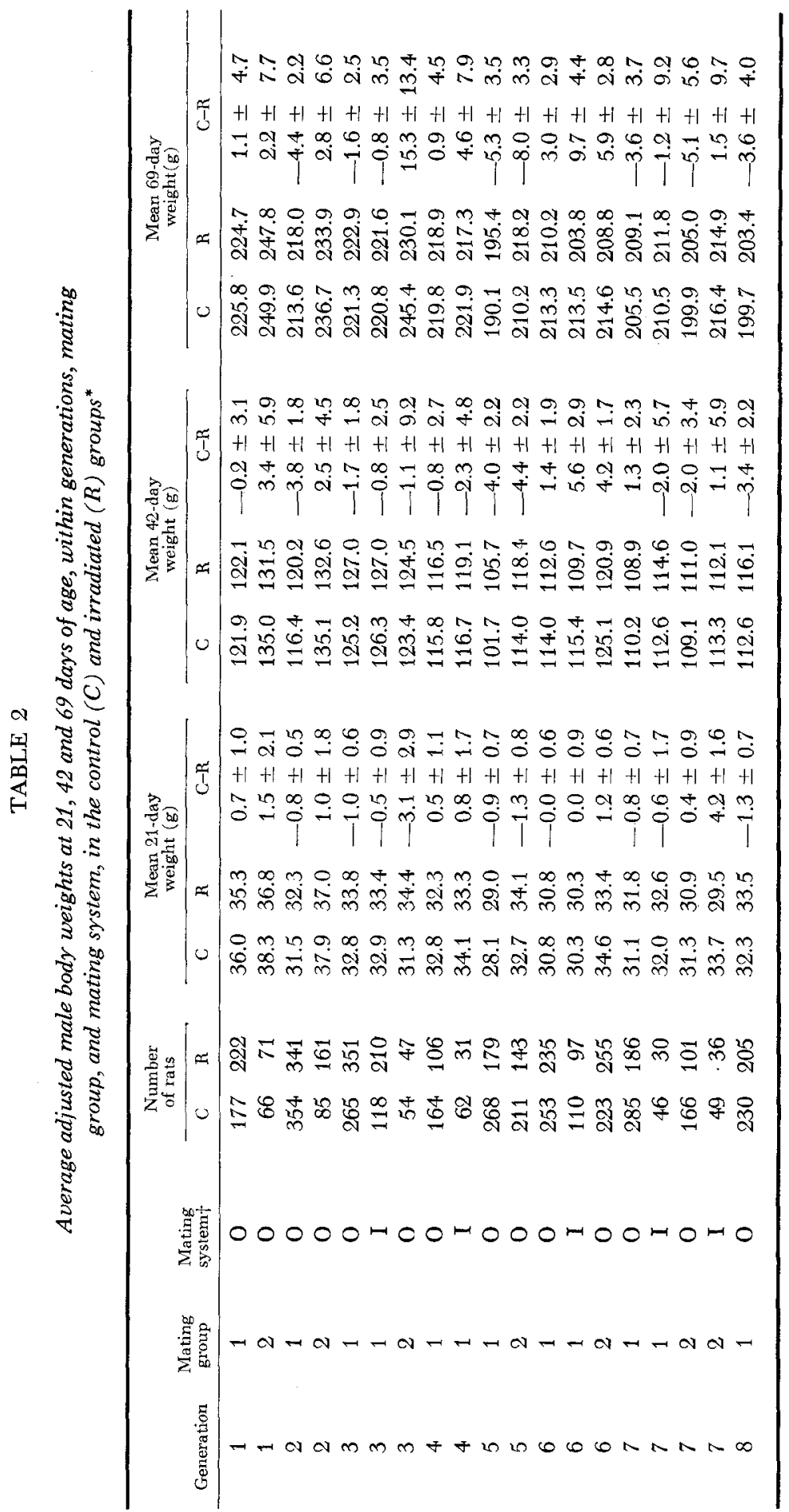


TABLE 3

Average adjusted female body weights at 21 and 42 days of age, within generation, mating group, and mating system, in the control (C) and irradiated $(\boldsymbol{R})$ groups $^{*}$

\begin{tabular}{|c|c|c|c|c|c|c|c|c|c|c|}
\hline \multirow{2}{*}{$\begin{array}{l}\text { Gener- } \\
\text { ation }\end{array}$} & \multirow{2}{*}{$\begin{array}{l}\text { Mating } \\
\text { group }\end{array}$} & \multirow{2}{*}{$\begin{array}{l}\text { Mating } \\
\text { system }+\end{array}$} & \multicolumn{2}{|c|}{$\begin{array}{c}\text { Number } \\
\text { of rats }\end{array}$} & \multicolumn{3}{|c|}{ Mean 21-day weight (g) } & \multicolumn{3}{|c|}{ Mean 42-day weight ( $\mathrm{g}$ ) } \\
\hline & & & C & $\mathbf{R}$ & C & $\mathrm{R}$ & $C-R$ & $\mathrm{C}$ & $\mathrm{R}$ & $\mathrm{C}-\mathrm{R}$ \\
\hline 1 & 1 & $\mathrm{O}$ & 180 & 182 & 35.3 & 33.9 & $1.4 \pm 1.1$ & 102.9 & 102.8 & $0.1 \pm 2.1$ \\
\hline 1 & 2 & 0 & 52 & 82 & 36.0 & 37.0 & $-1.0 \pm 2.2$ & 106.1 & 107.3 & $-1.2 \pm 4.6$ \\
\hline 2 & 1 & 0 & 333 & 386 & 30.5 & 31.0 & $-0.5 \pm 0.5$ & 97.9 & 98.7 & $-0.8 \pm 1.3$ \\
\hline 2 & 2 & 0 & 74 & 166 & 36.9 & 35.4 & $1.5 \pm 1.4$ & 107.5 & 107.5 & $0.0 \pm 2.4$ \\
\hline 3 & 1 & 0 & 323 & 386 & 32.4 & 32.9 & $-0.5 \pm 0.5$ & 103.2 & 103.2 & $-0.1 \pm 1.0$ \\
\hline 3 & 1 & I & 128 & 230 & 32.3 & 32.6 & $-0.3 \pm 0.8$ & 102.5 & 103.5 & $-1.0 \pm 1.5$ \\
\hline 3 & 2 & $\mathrm{O}$ & 71 & 60 & 30.4 & 35.3 & $-4.8 \pm 1.9$ & 99.9 & 107.9 & $-8.0 \pm 3.5$ \\
\hline 4 & 1 & $\mathrm{O}$ & 130 & 126 & 31.7 & 32.1 & $-0.3 \pm 1.0$ & 95.5 & 96.6 & $-1.1 \pm 2.0$ \\
\hline 4 & 1 & I & 72 & 37 & 31.8 & 32.8 & $-1.1 \pm 1.7$ & 99.3 & 101.4 & $-2.0 \pm 3.2$ \\
\hline 5 & 1 & 0 & 292 & 197 & 27.1 & 28.7 & $-1.6 \pm 0.7$ & 85.7 & 88.9 & $-3.3 \pm 1.6$ \\
\hline 5 & 2 & $\mathrm{O}$ & 225 & 148 & 32.3 & 32.3 & $-0.0 \pm 0.7$ & 94.8 & 95.6 & $-0.8 \pm 1.5$ \\
\hline 6 & 1 & 0 & 252 & 229 & 29.5 & 29.8 & $-0.2 \pm 0.6$ & 94.2 & 93.7 & $0.5 \pm 1.2$ \\
\hline 6 & 1 & I & 125 & 96 & 29.5 & 28.5 & $1.1 \pm 0.8$ & $\$ 4.2$ & 93.0 & $1.2 \pm 1.8$ \\
\hline 6 & 2 & $\mathrm{O}$ & 219 & 271 & 32.3 & 31.8 & $0.5 \pm 0.7$ & 98.8 & 98.2 & $0.6 \pm 1.5$ \\
\hline 7 & 1 & $\mathrm{O}$ & 315 & 227 & 30.5 & 30.5 & $0.1 \pm 0.6$ & 93.9 & 92.7 & $1.2 \pm 1.3$ \\
\hline 7 & 1 & I & 34 & 41 & 30.5 & 29.8 & $0.7 \pm 1.6$ & 93.3 & 98.4 & $-5.2 \pm 3.4$ \\
\hline 7 & 2 & 0 & 160 & 103 & 30.9 & 30.0 & $1.0 \pm 0.9$ & 93.3 & 95.5 & $-2.3 \pm 2.3$ \\
\hline 7 & 2 & I & 43 & 39 & 30.2 & 28.7 & $1.5 \pm 1.5$ & 91.2 & 89.3 & $2.0 \pm 4.0$ \\
\hline 8 & 1 & O & 261 & 227 & 31.0 & 32.0 & $-1.0 \pm 0.6$ & 93.4 & 97.2 & $-3.8 \pm 1.6$ \\
\hline 8 & 1 & I & 86 & 68 & 32.3 & 31.2 & $1.1 \pm 1.1$ & 97.5 & 96.3 & $1.2 \pm 2.8$ \\
\hline 8 & 2 & $\mathrm{O}$ & 160 & 162 & 30.4 & 29.9 & $0.6 \pm 0.9$ & 91.9 & 91.5 & $0.4 \pm 2.2$ \\
\hline 9 & 1 & 0 & 268 & 202 & 29.7 & 31.4 & $-1.6 \pm 0.7$ & 92.6 & 96.0 & $-3.4 \pm 1.5$ \\
\hline 9 & 1 & I & 102 & 37 & 29.6 & 29.8 & $-0.2 \pm 1.5$ & 92.8 & 92.1 & $0.7 \pm 3.1$ \\
\hline 9 & 2 & 0 & 347 & 266 & 31.8 & 32.5 & $-0.6 \pm 0.6$ & 96.7 & 97.7 & $-1.1 \pm 1.4$ \\
\hline 10 & 1 & 0 & 368 & 245 & 29.3 & 30.4 & $-1.1 \pm 0.7$ & 90.7 & 94.6 & $-3.9 \pm 1.7$ \\
\hline 10 & 1 & I & 119 & 104 & 30.6 & 32.9 & $-2.3 \pm 1.1$ & 92.7 & 98.8 & $-6.1 \pm 2.8$ \\
\hline 11 & 1 & $\mathrm{O}$ & 150 & 171 & 28.8 & 28.8 & $0.0 \pm 0.8$ & 90.7 & 91.8 & $-1.1 \pm 1.9$ \\
\hline 11 & 1 & I & 177 & 142 & 28.0 & 28.4 & $-0.3 \pm 0.8$ & 89.8 & 90.3 & $-0.4 \pm 1.9$ \\
\hline 11 & 2 & 0 & 68 & 57 & 31.4 & 31.9 & $-0.5 \pm 1.6$ & 89.5 & 91.4 & $-1.9 \pm 2.8$ \\
\hline 12 & 1 & 0 & 187 & 169 & 28.8 & 28.5 & $0.3 \pm 0.7$ & 90.1 & 90.3 & $-0.2 \pm 1.8$ \\
\hline 12 & 1 & I & 127 & 119 & 29.6 & 30.8 & $-1.2 \pm 0.9$ & 88.9 & 93.4 & $-4.6 \pm 2.1$ \\
\hline 12 & 2 & $\mathrm{O}$ & 55 & 41 & 32.2 & 33.6 & $-1.4 \pm 1.7$ & 92.8 & 98.7 & $-5.9 \pm 5.0$ \\
\hline 12 & 2 & I & 86 & 97 & 30.2 & 31.5 & $-1.3 \pm 1.2$ & 89.6 & 88.9 & $0.7 \pm 3.6$ \\
\hline 13 & 1 & 0 & 126 & 111 & 32.1 & 31.7 & $0.4 \pm 0.9$ & 93.7 & 95.5 & $-1.7 \pm 2.2$ \\
\hline 13 & 1 & I & 64 & 58 & 31.6 & 33.1 & $-1.4 \pm 1.3$ & 92.9 & 96.6 & $-3.7 \pm 3.1$ \\
\hline 13 & 2 & 0 & 36 & 43 & 34.8 & 34.2 & $0.6 \pm 2.0$ & 103.6 & 101.2 & $2.4 \pm 4.4$ \\
\hline 13 & 2 & I & 61 & 52 & 37.3 & 34.8 & $2.5 \pm 1.6$ & 101.8 & 97.8 & $3.9 \pm 3.7$ \\
\hline 14 & 1 & I & 107 & 86 & 31.8 & 32.6 & $-0.9 \pm 1.0$ & 91.5 & 93.5 & $-2.0 \pm 3.1$ \\
\hline
\end{tabular}

* Adjusted for age of dam, age of dam squared, parity, litter size at birth, and litter size at weaning.

tO $=$ "outbred," I = "inbred."

are heavier, and the age at vaginal opening was less in irradiated females. In many cases the differences are significant.

The adjusted means were analyzed to estimate the average heterozygous and 
TABLE 4

Average adjusted 69-day body weights and age at vaginal opening for females of control (C) and irradiated $(R)$ groups within generation, mating group, and mating system*

\begin{tabular}{|c|c|c|c|c|c|c|c|c|c|c|}
\hline \multirow{2}{*}{$\begin{array}{c}\text { Gener- } \\
\text { ation }\end{array}$} & \multirow{2}{*}{$\begin{array}{l}\text { Mating } \\
\text { group }\end{array}$} & \multirow{2}{*}{$\begin{array}{l}\text { Mating } \\
\text { system }\end{array}$} & \multicolumn{2}{|c|}{$\begin{array}{l}\text { Number } \\
\text { of rats }\end{array}$} & \multicolumn{3}{|c|}{ Mean 69-day weight (g) } & \multicolumn{3}{|c|}{ Mean age at vaginal opening(days) } \\
\hline & & & $\mathrm{C}$ & $R$ & C & $\overline{\mathrm{R}}$ & $\mathrm{C}-\mathrm{R}$ & C & $\mathbf{R}$ & $\mathrm{C}-\mathrm{R}$ \\
\hline 1 & 1 & $\mathrm{O}$ & 180 & 182 & 161.6 & 160.9 & $0.7 \pm 2.4$ & 35.7 & 35.8 & $-0.2 \pm 0.4$ \\
\hline 1 & 2 & 0 & 52 & 82 & 168.6 & 169.5 & $-0.9 \pm 4.8$ & 34.7 & 35.7 & $-1.0 \pm 0.7$ \\
\hline 2 & 1 & 0 & 333 & 386 & 155.9 & 157.0 & $-1.1 \pm 1.4$ & 37.4 & 37.3 & $0.2 \pm 0.4$ \\
\hline 2 & 2 & $\mathrm{O}$ & 74 & 166 & 163.9 & 164.4 & $-0.5 \pm 3.1$ & 35.8 & 36.1 & $-0.3 \pm 0.5$ \\
\hline 3 & 1 & $\mathrm{O}$ & 323 & 386 & 157.2 & 157.3 & $-0.1 \pm 1.2$ & 35.7 & 35.6 & $0.1 \pm 0.2$ \\
\hline 3 & 1 & I & 128 & 230 & 156.4 & 158.0 & $-1.5 \pm 1.8$ & 35.7 & 35.4 & $0.2 \pm 0.3$ \\
\hline 3 & 2 & $\mathrm{O}$ & 71 & 60 & 157.6 & 166.5 & $-8.9 \pm 5.1$ & 35.3 & 35.0 & $0.3 \pm 0.6$ \\
\hline 4 & 1 & $\mathrm{O}$ & 130 & 126 & 151.8 & 151.9 & $-0.1 \pm 2.1$ & 37.6 & 37.9 & $-0.3 \pm 0.6$ \\
\hline 4 & 1 & I & 72 & 37 & 156.4 & 158.8 & $-2.4 \pm 3.4$ & 37.6 & 36.9 & $0.7 \pm 1.0$ \\
\hline 5 & 1 & $\mathrm{O}$ & 292 & 197 & 138.9 & 143.2 & $-4.3 \pm 1.8$ & 40.5 & 40.0 & $0.5 \pm 0.5$ \\
\hline 5 & 2 & O & 225 & 148 & 150.2 & 151.3 & $-1.0 \pm 1.6$ & 37.8 & 37.3 & $0.5 \pm 0.4$ \\
\hline 6 & 1 & $\mathrm{O}$ & 252 & 229 & 148.1 & 148.7 & $-0.6 \pm 1.4$ & 38.0 & 38.6 & $-0.6 \pm 0.3$ \\
\hline 6 & 1 & I & 125 & 96 & 148.8 & 147.2 & $1.7 \pm 2.1$ & 37.8 & 38.7 & $-0.9 \pm 0.5$ \\
\hline 6 & 2 & o & 219 & 271 & 148.0 & 148.5 & $-0.5 \pm 1.8$ & 38.1 & 38.0 & $0.1 \pm 0.4$ \\
\hline 7 & 1 & 0 & 315 & 227 & 150.7 & 147.3 & $3.4 \pm 1.9$ & 37.8 & 39.0 & $-1.2 \pm 0.4$ \\
\hline 7 & 1 & I & 34 & 41 & 150.9 & 156.8 & $-5.9 \pm 5.0$ & 37.4 & 37.0 & $0.4 \pm 0.9$ \\
\hline 7 & 2 & $\mathrm{O}$ & 160 & 103 & 149.3 & 150.3 & $-1.0 \pm 2.8$ & 38.9 & 38.6 & $0.2 \pm 0.7$ \\
\hline 7 & 2 & I & 43 & 39 & 148.5 & 139.4 & $9.1 \pm 4.9$ & 38.6 & 40.1 & $-1.5 \pm 1.2$ \\
\hline 8 & 1 & $\mathrm{O}$ & 261 & 227 & 142.4 & 148.0 & $-5.6 \pm 1.9$ & 38.3 & 36.9 & $1.4 \pm 0.4$ \\
\hline 8 & 1 & I & 86 & 68 & 148.2 & 142.8 & $5.4 \pm 3.4$ & 37.0 & 36.1 & $0.9 \pm 0.8$ \\
\hline 8 & 2 & 0 & 160 & 162 & 148.0 & 148.3 & $-0.4 \pm 2.8$ & 37.9 & 37.6 & $0.2 \pm 0.6$ \\
\hline 9 & 1 & o & 268 & 202 & 145.4 & 152.1 & $-5.7 \pm 1.8$ & 37.7 & 36.7 & $1.0 \pm 0.4$ \\
\hline 9 & 1 & I & 102 & 37 & 145.1 & 143.9 & $2.3 \pm 3.6$ & 37.3 & 37.3 & $-0.0 \pm 0.8$ \\
\hline 9 & 2 & 0 & 347 & 266 & 151.1 & 152.0 & $-0.9 \pm 1.8$ & 36.6 & 36.1 & $0.4 \pm 0.4$ \\
\hline 10 & 1 & $\mathrm{O}$ & 368 & 245 & 139.1 & 143.2 & $-4.2 \pm 2.2$ & 38.4 & 38.0 & $0.4 \pm 0.5$ \\
\hline 10 & 1 & I & 119 & 104 & 138.5 & 147.9 & $-9.5 \pm 3.5$ & 38.7 & 37.5 & $1.1 \pm 0.8$ \\
\hline 11 & 1 & 0 & 150 & 171 & 144.1 & 146.3 & $-2.2 \pm 2.5$ & 38.2 & 37.8 & $0.3 \pm 0.6$ \\
\hline 11 & 1 & I & 177 & 142 & 143.2 & 142.6 & $0.6 \pm 2.5$ & 38.5 & 38.6 & $-0.0 \pm 0.6$ \\
\hline 11 & 2 & 0 & 68 & 57 & 146.6 & 149.4 & $-2.8 \pm 3.5$ & 37.9 & 36.4 & $1.6 \pm 0.9$ \\
\hline 12 & 1 & o & 187 & 169 & 143.9 & 143.8 & $0.1 \pm 2.5$ & 36.9 & 37.2 & $-0.3 \pm 0.6$ \\
\hline 12 & 1 & I & 127 & 119 & 140.9 & 145.5 & $-4.7 \pm 3.0$ & 37.0 & 36.1 & $0.9 \pm 0.7$ \\
\hline 12 & 2 & $\mathrm{O}$ & 55 & 41 & 149.4 & 151.5 & $-2.1 \pm 5.5$ & 37.4 & 37.5 & $-0.0 \pm 1.4$ \\
\hline 12 & 2 & I & 86 & 97 & 142.6 & 146.1 & $-3.5 \pm 3.9$ & 39.0 & 39.0 & $-0.1 \pm 1.0$ \\
\hline 13 & 1 & $\mathrm{O}$ & 126 & 111 & 149.2 & 152.6 & $-3.4 \pm 2.8$ & 36.8 & 36.8 & $0.0 \pm 0.6$ \\
\hline 13 & 1 & I & 64 & 58 & 149.3 & 150.7 & $-1.4 \pm 3.9$ & 37.0 & 36.1 & $0.8 \pm 0.9$ \\
\hline 13 & 2 & $\mathrm{O}$ & 36 & 43 & 155.5 & 158.8 & $-3.3 \pm 5.2$ & 36.6 & 36.9 & $-0.3 \pm 1.3$ \\
\hline 13 & 2 & I & 61 & 52 & 158.1 & 155.9 & $2.1 \pm 4.3$ & 37.3 & 38.2 & $-1.0 \pm 1.1$ \\
\hline 14 & 1 & I & 107 & 86 & 151.4 & 154.2 & $-2.8 \pm 3.0$ & & . & . \\
\hline
\end{tabular}

* Adjusted for age of dam, age of dam squared, parity, litter size at birth, and litter size at weaning.

+O = "outbred," I = "inbred."

homozygous effects per roentgen of cumulative exposure, as well as the average homozygous effects of spontaneous mutations. The results of these analyses are presented in Tables 5 and 6 , for males and females, respectively. 
TABLE 5

Average effects of induced and spontaneous mutations on male body weights

\begin{tabular}{|c|c|c|c|c|}
\hline \multirow[b]{3}{*}{ Trait } & \multicolumn{3}{|c|}{ Average cumulative effect $(g)$} & \multirow[b]{3}{*}{$\begin{array}{c}\text { Test for } \\
\text { nonlinearity }\end{array}$} \\
\hline & \multirow{2}{*}{ 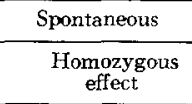 } & \multicolumn{2}{|c|}{ Induced (/gamete/100r) } & \\
\hline & & $\begin{array}{c}\text { Heterozygous } \\
\text { effect }\end{array}$ & $\begin{array}{c}\text { Homozygous } \\
\text { effect }\end{array}$ & \\
\hline \multicolumn{5}{|l|}{ Body weight } \\
\hline 21-day & $0.10 \pm 0.07$ & ${ }^{* *} 0.03 \pm 0.01$ & $0.02 \pm 0.10$ & $P \sim 0.10$ \\
\hline 42-day & ${ }^{* * 0} 0.58 \pm 0.21$ & $* * 0.09 \pm 0.02$ & $-0.24 \pm 0.30$ & $\mathbf{P} \sim 0.70$ \\
\hline 69-day & $0.37 \pm 0.37$ & $0.07 \pm 0.04$ & $-0.12 \pm 0.54$ & $\mathrm{P} \sim 0.20$ \\
\hline
\end{tabular}

+ Test of goodness of fit to the linear model.

$* * \mathrm{P}<.01$.

The tests for nonlinearity of regression were close to significance for the traits 21-day and 69-day weights in females. This suggests that the simple model assumed here may not be completely adequate to fit the data. Since this is a test of the entire model, it is difficult to say what, if any, particular assumption(s) is incorrect. The linear effects accounted for a significant portion of the variability in most of these analyses. It is felt that the parameters estimated in these analyses give a fairly good indication of the effects of irradiation on these traits.

The most striking result is the evidence for heterozygous effect of induced mutations. These results point to an increase in body weight in both sexes and to a decrease in age at vaginal opening.

In contrast to the heterozygous effects, the homozygous effects of induced mutations seemed to be to decrease body weights and to increase age at vaginal opening. The magnitudes of the homozygous effects are considerably greater than the heterozygous effects in most cases.

The estimated homozygous effects of spontaneous mutations was in the direc-

TABLE 6

Average effects of induced and spontaneous mutations on female body weights and age at vaginal opening

\begin{tabular}{|c|c|c|c|c|}
\hline \multirow[b]{3}{*}{ Trait } & \multicolumn{3}{|c|}{ Average cumulative effect (g, day) } & \multirow[b]{3}{*}{$\begin{array}{c}\text { Test for } \\
\text { nonlinearity } \dagger\end{array}$} \\
\hline & \multirow{2}{*}{ 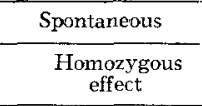 } & \multicolumn{2}{|c|}{ Induced (/gamete/100r) } & \\
\hline & & $\begin{array}{c}\text { Heterozygous } \\
\text { effect }\end{array}$ & $\begin{array}{c}\text { Homozygous } \\
\text { effect }\end{array}$ & \\
\hline \multicolumn{5}{|l|}{ Body weight } \\
\hline 21-day & $0.01 \pm 0.07$ & $0.01 \pm 0.01$ & $0.07 \pm 0.11$ & $\mathrm{P}=0.05$ \\
\hline 42-day & $0.01 \pm 0.15$ & ${ }^{*} 0.04 \pm 0.02$ & $0.09 \pm 0.23$ & $P \sim 0.40$ \\
\hline 69-day & $0.04 \pm 0.20$ & ${ }^{* *} 0.07 \pm 0.02$ & $-0.31 \pm 0.31$ & $\mathrm{P} \sim 0.06$ \\
\hline $\begin{array}{l}\text { Age at vaginal } \\
\text { opening }\end{array}$ & $-0.04 \pm 0.04$ & $-0.01 \pm 0.01$ & $0.02 \pm 0.07$ & $\mathbf{P} \sim 0.45$ \\
\hline
\end{tabular}

+ Test of goodness of fit to the linear model.

$* \mathbf{P}<.01$. 
tion of increased body weight and decreased age at vaginal opening. These effects attained significance only in the case of 42-day body weight of males.

Increased body weight in the progeny of irradiated males has been reported in both mice (TOUChBerry and VERLEY 1964) and rats (NEwCOMBE and MCGREGOR 1965). Although the direction of the effects of irradiation on body weight found in their experiments is consistent with the present results, the magnitude of the effects was greater in their studies. In their studies irradiated spermatozoa were sampled instead of spermatogonia. Since mature sperm are known to be more mutable than spermatogonia, perhaps this difference should not be considered surprising.

SCHLAger, Roderick and Storer (1966) studied the effect of spermatogonial irradiation on body weight in mouse populations formed by crossing four inbred lines. A single dose of $900 \mathrm{r}$ was given to males each generation in a series of small sub-lines. Preliminary results indicated that ancestral spermatogonial irradiation decreased body weight. Since there was no deliberate inbreeding, these effects were presumably due to the heterozygous effects of induced mutations. Their results appear to be contradictory to the present findings. GREEN (1968) studied these same lines with respect to 60-day body weight and embryonic mortality. After varying numbers of generations of irradiation, the sub-lines were maintained for several generations by random mating without additional irradiation. The "test" animals were produced by full-sib mating. A significant decrease in male body weight relative to the controls was observed. A smaller, nonsignificant decrease was observed in female body weight. Unfortunately, the experimental design did not permit the distinction between heterozygous and homozygous effects. Because of this limitation and also because the author made different assumptions about the rate of accumulation of mutants affecting body weight than are made in the present study, it is difficult to make comparisons. However, to a first approximation, his results appear to be consistent with the homozygous effects of induced mutations on 69-day weights in the present study.

Cox (1968) reported that the mean 154-day body weight of pigs whose sires were given $300 \mathrm{r}$ spermatogonial irradiation was $1 \%$ less than controls in the Duroc breed and $0.5 \%$ less in the Hampshire breed. Only the difference in the Duroc breed was significant. These differences are opposite to the expectation based on the increases observed in the present study.

It appears that the average heterozygous and homozygous effects of induced mutations in the present study are opposite in direction, although the significance of this is subject to question. If the effect were real, the most obvious explanation would be that induced mutations exhibit overdominance with respect to these traits. If overdominance is the principal kind of gene action, selection for increased body weight (or decreased age at vaginal opening) should lead to an intermediate equilibrium gene frequency such that when selection ceased to be effective the population would still be segregating. Such a population would be responsive to reverse selection. An alternative hypothesis would postulate two classes of induced mutations. The first class would have positive additive effects on body weight. The other class would have negative recessive effects on body 
weight. If the alternative hypothesis is correct, selection for increased body weight should fix the first class of mutations and eliminate the second class leading to fixation at the selection limit. In this case reverse selection would be ineffective. Thus, selection would appear to be an effective way to distinguish between these two hypotheses as well as to answer the question as to how much selection response can be obtained after a given amount of irradiation. The latter will depend on the number of induced mutations and the magnitude of their individual effects.

Effects on within-litter variances: The within-litter mean squares for the body weights and age at vaginal opening were computed for each group classified by sex, generation-mating group, mating system and treatment. Each mean square in the irradiated groups was compared with the mean square in the corresponding control group on the basis of direction and significance of differences. The $F$ test was used in judging significance. Comparing the frequencies of positive differences and "significant" differences from all the analyses should provide a robust test for an increase in variance. Out of the 264 comparisons, the irradiated mean square exceeded the control value 145 times ( $55 \%$ ). If all these comparisons were independent, the probability of obtaining this many or more positive differences $(\mathrm{R}-\mathrm{C})$ would be about 0.05 . Since not all of these comparisons are independent, the true probability is somewhat greater. The irradiated mean square was "significantly" greater $(P<.05)$ than the control mean square in 32 cases, while the reverse was true in 19 cases. The chance probability of obtaining a difference as large as or larger than this and in the same direction is about 0.03 . Again, it must be recalled that the assumption of independence is not strictly valid. It seems safe to conclude that an increase in variance due to irradiation is suggested by the data. The increased variances appear to be concentrated among inbred males. One would expect the variance increase to be expressed mainly in the inbreds if induced mutations are recessive, and recessive X-linked mutations would be expressed more often in males than in females.

In order to estimate any changes in variance, a weighted multiple regression analysis was performed paralleling the analysis done on the means. Differences between control and irradiated mean squares, within generation-mating groups, were regressed on the heterozygous and homozygous exposures. The results of these analyses are presented in Tables 7 and 8 for males and females, respectively. The interpretation of these analyses is complicated by the fact that since the dependent variables are variances, the assumption of normality is invalid. Therefore, the significance tests must be regarded as only approximate. Variance increases in the male body weights associated with heterozygous and homozygous radiation exposure were observed but were significant only for homozygous exposure in 21-day weights. There is little or no evidence of a variance increase in the female analysis.

Effects on offspring-parent regression: The regressions of offspring on parent for body weight and age at vaginal opening were calculated on the unadjusted data for each sub-group classified by generation, treatment line, mating system, sex of offspring and sex of parent. The regression of offspring on sire was gener- 
TABLE 7

Effects of induced and spontaneous mutations on the within-litter variance of male body weights

\begin{tabular}{|c|c|c|c|c|}
\hline \multirow[b]{3}{*}{ Trait } & \multicolumn{3}{|c|}{ Average cumulative effect } & \multirow[b]{3}{*}{$\begin{array}{c}\text { Test for } \\
\text { nonlinearity }\end{array}$} \\
\hline & \multirow{2}{*}{$\begin{array}{c}\text { Spontaneous } \\
\begin{array}{c}\text { Homozygous } \\
\text { effect }\end{array}\end{array}$} & \multicolumn{2}{|c|}{ Induced (/gamete/100r) } & \\
\hline & & $\begin{array}{l}\text { Heterozygous } \\
\text { effect }\end{array}$ & $\begin{array}{l}\text { Homozygous } \\
\text { effect }\end{array}$ & \\
\hline \multicolumn{5}{|l|}{ Body weight } \\
\hline 21-day & $-0.18 \pm 0.15$ & $0.02 \pm 0.02$ & ${ }^{*} 0.52 \pm 0.20$ & $\mathrm{P} \sim 0.30$ \\
\hline 42-day & *-10.42 \pm 4.01 & $0.34 \pm 0.45$ & $8.74 \pm 6.16$ & $\mathbf{P}<0.001$ \\
\hline 69-day & $-20.61 \pm 13.19$ & $1.13 \pm 1.41$ & $1.17 \pm 20.42$ & $\mathbf{P}<0.01$ \\
\hline
\end{tabular}

+ Test of goodness of fit to the linear model.

${ }^{*} \mathrm{P}<.05$.

ally small and nonsignificant as would be expected in a highly inbred line. The regression of offspring on dam was generally larger and sometimes significant. The latter probably reflects a positive environmental covariance. This could be explained if the larger dams produced more milk for their progeny than the smaller dams.

In order to test the null hypothesis that irradiation has not increased the genetic variance, the differences between the irradiated and control regression coefficients were regressed on the cumulative irradiation exposure by a weighted regression analysis. For the outbreds, this would measure one half the increase in heritability per roentgen of radiation given to the male parent.

The results, presented in Table 9, show a consistent increase in the regression of outbred offspring on parent for weights (one exception in 21-day weights), attaining significance in two cases. The results for the inbreds appear to be different, with most of the values smaller than those for the outbreds, five of them negative, two of them significantly so. If the genetic variance were purely additive in nature, the regression of offspring on parent would be enhanced for the

TABLE 8

Effects of induced and spontaneous mutations on the within-litter variance of female body weights and age at vaginal opening

\begin{tabular}{|c|c|c|c|c|}
\hline \multirow[b]{3}{*}{ Trait } & \multicolumn{3}{|c|}{ Average cumulative effect } & \multirow[b]{3}{*}{$\begin{array}{c}\text { Test for } \\
\text { nonlinearity }\end{array}$} \\
\hline & \multirow{2}{*}{$\begin{array}{c}\text { Spontaneous } \\
\begin{array}{c}\text { Homozygous } \\
\text { effect }\end{array}\end{array}$} & \multicolumn{2}{|c|}{ Induced (/gamete/100r) } & \\
\hline & & $\begin{array}{l}\text { Heterozygous } \\
\text { effect }\end{array}$ & $\begin{array}{c}\text { Homozygous } \\
\text { effect }\end{array}$ & \\
\hline \multicolumn{5}{|l|}{ Body weight } \\
\hline 21-day & $-0.16 \pm 0.18$ & $0.01 \pm 0.02$ & $0.19 \pm 0.25$ & $\mathbf{P}<0.001$ \\
\hline 42-day & $-2.66 \pm 2.05$ & $0.03 \pm 0.24$ & $-2.13 \pm 3.37$ & $\mathbf{P}<0.001$ \\
\hline 69-day & $-6.01 \pm 4.09$ & $-0.24 \pm 0.49$ & $0.93 \pm 6.35$ & $\mathbf{P}<0.001$ \\
\hline \multicolumn{5}{|l|}{ Age at vaginal } \\
\hline opening & $-0.33 \pm 0.21$ & $-0.00 \pm 0.03$ & $-0.31 \pm 0.38$ & $\mathrm{P}<0.001$ \\
\hline
\end{tabular}

t Test of goodness of fit to the linear model. 
TABLE 9

Increase in regression of offspring on parent per roentgen of cumulative exposure

\begin{tabular}{|c|c|c|c|c|c|}
\hline \multirow[b]{2}{*}{ Relationship } & \multirow[b]{2}{*}{$\begin{array}{l}\text { Mating } \\
\text { system-1 }\end{array}$} & \multicolumn{4}{|c|}{ Trait: } \\
\hline & & $\begin{array}{l}\text { 21-day } \\
\text { weight }\end{array}$ & $\begin{array}{l}\text { 42-day } \\
\text { weight }\end{array}$ & $\begin{array}{l}\text { 69-day } \\
\text { weight }\end{array}$ & $\begin{array}{l}\text { Age at } \\
\text { vaginal opening }\end{array}$ \\
\hline sire-son & 0 & $-.07 \pm 0.10$ & $0.04 \pm 0.15$ & $0.20 \pm 0.12$ & \\
\hline sire-son & I & $* *-.57 \pm 0.18$ & $0.02 \pm 0.24$ & $0.04 \pm 0.23$ & \\
\hline sire-daughter & $\mathrm{O}$ & $0.14 \pm 0.09$ & ${ }^{*} 0.15 \pm 0.06$ & $0.12 \pm 0.07$ & $\ldots \ldots$ \\
\hline sire-daughter & I & $*-.45 \pm 0.23$ & $0.04 \pm 0.22$ & $-.10 \pm 0.15$ & \\
\hline dam-son & $\mathrm{O}$ & $0.19 \pm 0.20$ & $0.39 \pm 0.26$ & $* * 0.61 \pm 0.18$ & \\
\hline dam-son & I & $-.09 \pm 0.22$ & $0.03 \pm 0.37$ & $0.11 \pm 0.62$ & $\ldots \ldots \ldots$ \\
\hline dam-daughter & 0 & $0.30 \pm 0.17$ & $0.17 \pm 0.11$ & $0.19 \pm 0.13$ & $-.24 \pm 0.17$ \\
\hline dam-daughter & I & $-.06 \pm 0.23$ & $0.11 \pm 0.25$ & $0.32 \pm 0.25$ & $0.13 \pm 0.17$ \\
\hline
\end{tabular}

$\div \mathrm{O}=$ outbred, $\mathrm{I}=$ inbred.

$\$$ Each value has been multiplied by $10^{4}$.

$* \mathrm{P}<.05$.

$* * \mathrm{P}<.01$.

inbred offspring ( $\left.R_{\mathrm{op}}=.67\right)$. The results indicate the opposite of what would be expected under the additive hypothesis. It is concluded that nonadditive genetic variance is probably being expressed. Real negative genetic covariances between inbred and non-inbred relatives can occur if overdominance is the prevailing kind of gene action. The present results point in this direction.

When the effects of irradiation on the means, within-litter variances, and regression of offspring on parent are considered jointly, the results are most easily interpreted by assuming overdominance of induced mutations affecting body weight (adjusted for size of litter, parity and age of dam). The homozygous effects of these mutations appear to decrease body weight to a greater extent than the heterozygous effects increase it. Thus, selection for increased body weight would be expected to increase the gene frequency of the mutant alleles to some intermediate value less than 0.5 . The results of selection for low body weight are less predictable, but would be expected to lead to fixation of either the mutant or the preexisting allele.

The results of the present experiment hold out some hope that X-irradiation could be used in conjunction with artificial selection for the more rapid improvement of domestic animals. An estimate of the cost of such a program in terms of the induced genetic load has also been obtained (TAYlor and Chapman 1969). Only with a knowledge of the potential gains and their costs can sound decisions be made on the practical value of this approach.

The authors are indebted to Dr. N. E. Morton for his part in the design of the experiment, to Dr. JANET HANSEN who collected the first four generations of data, to Dr. J. F. CRow for many helpful discussions concerning the analysis and interpretation of the data, to Mr. L. P. JoHnson for his programming assistance, and to Dr. JANICE Davison for help in analyzing part of the data.

Significant effects of cumulative spermatogonial irradjation were observed for 
age of vaginal opening and body weights (adjusted for litter size, parity and age of dam). Analyses of the means, the within-litter variances, and the covariances between offspring and parent, indicate that the average heterozygous effects of induced mutations are to increase body weights and decrease age at vaginal opening, while the average homozygous effects are to decrease body weights and to increase age at vaginal opening. Overdominance of induced mutations with respect to these quantitative traits is, therefore, indicated.

\section{LITERATURE CITED}

Cox, D. F., 1968 The effect of paternal irradiation on body weight and depth of fat in pigs. Genetics 58: 271-274.

Green, E. L., 1968 Body weights and embryonic mortality in an irradiated population of mice. Mutation Res. 6: 437-448.

Haldane, J. B. S., 1936 The amount of heterozygosis to be expected in an approximately pure line. J. Genet. 32 : 375-391.

Newcombe, H. B., and J. F. McGregor, 1965 Heritable effects of radiation on body weight in rats. Genetics 52: $851-860$.

Schlager, G., T. H. Roderick, and J. H. Storer, 1966 Longevity and body weights of mice with ancestral spermatogonial X-irradiation. Mutation Res. 3 : 230-236.

TAylor, B. A., and A. B. Chapman, 1969 The frequency of $\mathrm{X}$ ray-induced dominant and recessive lethal mutations in the rat. Genetics $63: 455-466$.

Touchberry, R. W., and F. A. Verlex, 1964 Some effects of X-irradiation in successive generations on an inbred and a hybrid population of mice. Genetics 50: 1187-1209. 